\title{
Dynamic Load and Storage Integration
}

\author{
R.E. Hebner, Fellow, IEEE, K. Davey, Fellow, IEEE, J. Herbst, D. Hall, J. Hahne, D. Surls, and A. Ouroua
}

\begin{abstract}
Modern technology combined with the desire to minimize the size and weight of a ship's power system are leading to renewed interest in more electric or all electric ships. An important characteristic of the emerging ship power system is an increasing level of load variability, with some future pulsed loads requiring peak power in excess of the available steadystate power. This inevitably leads to the need for some additional energy storage beyond that inherent in the fuel.
\end{abstract}

With the current and evolving technology, it appears that storage will be in the form of batteries, rotating machines, and capacitors. All of these are in use on ships today and all have enjoyed significant technological improvements over the last decade. Moreover all are expected to be further enhanced by today's materials research. A key benefit of storage is that, when it can be justified for a given load, it can have additional beneficial uses such as ride-through capability to restart a gas turbine if there is an unanticipated power loss; alternatively, storage can be used to stabilize the power grid when switching large loads. Knowing when to stage gas turbine utilization versus energy storage is a key subject in this paper. The clear need for storage has raised the opportunity to design a comprehensive storage system, sometimes called an energy magazine, that can combine intermittent generation as well as any or all of the other storage technologies to provide a smaller, lighter and better performing system than would individual storage solutions for each potential application.

Index Terms-flywheel; electric ship; pulsed alternator; battery; capacitor; energy magazine; energy storage; microgrid; power system

\section{BACKGROUND}

When the sailing ship transitioned from the backbone of ocean transportation to a recreational asset, ships became large mobile energy storage systems. They no longer harvested ambient wind energy. Rather, they carried their energy with them as fuel. Initially, the energy stored in the fuel was used nearly exclusively for propulsion.

This situation began to change with the introduction of radar, which can be a relatively large load requiring electrical power. The growth of computing and telecommunications added more electrical loads. Propulsion, electrical based weapons, ship wide system components, and even hydraulic drives soon followed as additional loads to be handled by the ship's fuel. If the ship were a warship, it also maintained chemical propellants. Today, ships are becoming increasingly dependent on electricity to function efficiently and effectively.

Nearly all, if not all, of the energy needed to operate a ship is stored in the fuel it carries. With much of the energy being distributed as electricity, the ship is truly an isolated microgrid. Delivery of the stored chemical energy as electricity to the loads in a ship requires an electromechanical system. That system typically includes energy storage, ranging from accumulators in hydraulic systems, to batteries, to electromechanical storage in EMALS [1,2], which is the electromagnetic aircraft launch system being installed on the emerging class of carriers.

Energy storage beyond that stored in the fuel can be important in a variety of roles in electric ship operations to provide the following:

- Load support during power generation loss, i.e., the classic uninterruptable power supply function,

- Faster response time to differential load changes. In this application, storage can be used to smooth load variations to provide longer life for a gas turbine. In the extreme, it can be used to provide time for the gas turbine to respond to large step changes in the load.

- Delivery pulsed power far in excess of the continuous power rating.

- Higher operational efficiency by optimizing gas turbine fuel consumption. An example would be the operation of only one gas turbine at low speeds. Storage provides "dark start” capability

- Cleaner propulsion under certain conditions such as port entry where strict air quality codes exist.

As the electric, mechanical, and hydraulic power systems in ships have grown in size and power consumption, ship designers face the challenge of how to maintain a reasonable payload, be the payload passengers, cargo, or weapons systems, without employing a larger hull.

A promising approach to reducing size and cost is to develop an all electric ship [3-5] in which the fuel is used to generate electricity and electricity is used to power all other loads. This requires electrical energy storage. This approach is increasingly interesting due to the advances in power electronics and controls. Combining advanced storage, power electronics and controls is a key research area that promises significant improvements in total system size and weight.

This paper highlights three aspects of the situation. First, it reviews the various storage options, considering how the various attributes of these options are relevant to shipboard application. Second a brief review is made of trades between the costs of fuel storage and the costs of energy storage at a fundamental level. Finally, explicit examples are discussed of emerging systems that could reduce the impact on ship volume. 


\section{STORAGE TECHNOLOGY}

Shipboard energy is stored electrically, mechanically, magnetically, chemically and electrochemically. In addition to the fuel, the primary larger-scale energy storage technologies used on ships today are capacitors, rotating machines, and batteries. Inductors are used in power electronic and electronic circuits. Due to the low energy density, however, their use is typically limited to lower power circuits where they can be small.

Each technology has unique attributes. Important among these are their power and energy density. Energy density is a measure of the volume required to store a given amount of energy. Passive components, like capacitors and inductors, have the lowest energy density. Older technologies like steel flywheels and $\mathrm{NiH}$ batteries are better than passive components, but are still low. The SMES (Superconducting Magnetic Energy Storage) has a lower energy density [6] than other technologies due to a constitutive property, namely the permeability of free space; B has a practical upper limit $<10$ T over any sizeable volume and $\mu_{0}$ will never be smaller than $4 \pi \cdot 10^{-7}$. This yields an upper limit on energy density of $1 / 2 \mathrm{~B}^{2} / \mu_{0}$ of $39.8 \mathrm{MJ} / \mathrm{m}^{3}$.

Lithium ion batteries, ultracapacitors, and composite flywheels are currently the most energy dense. So if the challenge is to store the most energy in the smallest space, these are the key technologies. But, energy density is not always the critical parameter. In many applications, the energy must be delivered in a short time. In these cases, power density is more critical than energy density.

The power density, however, does not scale like the energy density. In general, if the stored energy must be delivered in less than a microsecond, capacitors are the storage medium of choice. For longer pulses, flywheels and ultracapacitors are second in speed of delivery. Finally, batteries tend to be the least power dense.

Being less power dense does not, however, mean that batteries cannot deliver the power in the required time. There are two approaches typically considered when more power is needed than can be extracted from a minimum-energy battery array. The first is to add more batteries. More batteries permit more current per unit time at the design voltage and so increase the power. The penalty is a larger system size. The second alternative is to use a hybrid system. This approach combines batteries to take advantage of their energy density with ultracapacitors or flywheels to take advantage of their power density. Since the energy density of batteries, flywheels, and ultracapacitors is comparable, this approach generally leads to a larger system than either a flywheel or ultracapacitor solution. The relative attributes of the various technologies are summarized in Figure 1.

These technologies continue to improve and nanotechnology shows particular promise as carbon nanotubes are being spun into longer and longer fibers [7] that may eventually be able to replace the conventional carbon fibers used today. Similarly, adding carbon nanotubes or other nanoparticles to the resin in the composite [8] is yielding enhanced performance. The use of carbon nanotubes for stronger composites holds promise but significant challenges in manufacturing the fibers and composites remain.

Nanotechnology is also promising to improve battery performance. For example, materials research suggests more rapid charge and discharge times and longer cycle life may make batteries even more appropriate for high power applications in the future.

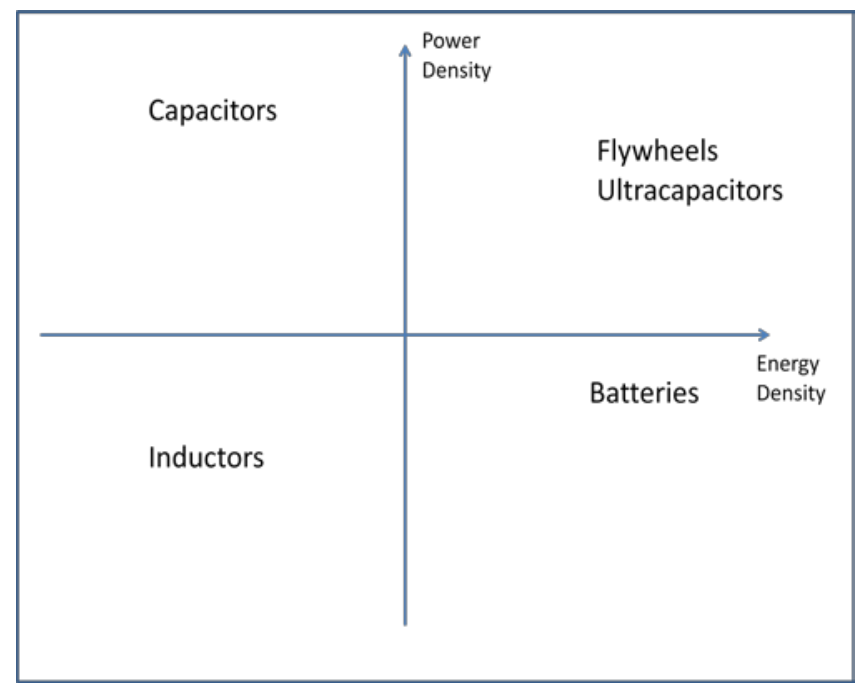

Figure 1: Chart showing notional attributes of storage technologies with respect to power and energy density.

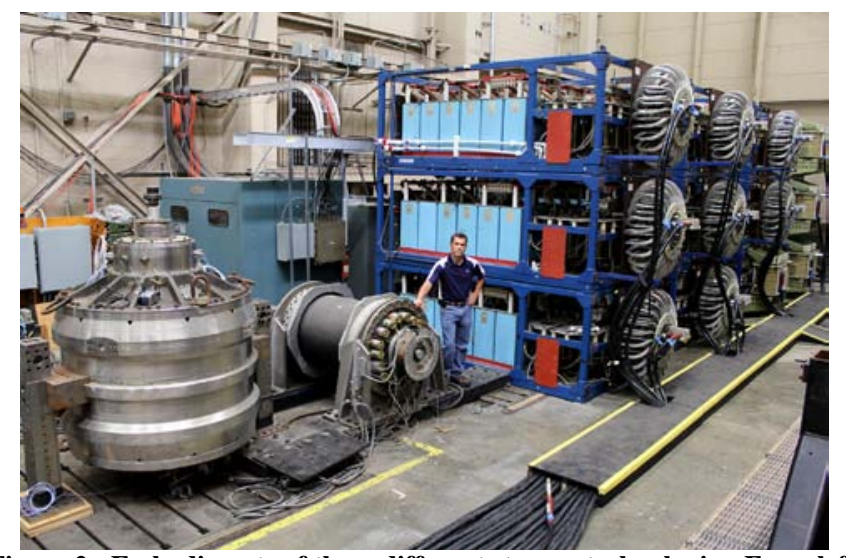

Figure 2: Embodiments of three different storage technologies. From left to right are a flywheel, a pulsed alternator, and a capacitor bank. The flywheels stores $480 \mathrm{MJ}$, The pulsed alternator stores $22 \mathrm{MJ}$. The capacitor bank stores $12 \mathrm{MJ}$.

Figure 2 is an approximate representation showing that realistic embodiments of capacitors and rotating machines generally follow the predictions from fundamental considerations. As predicted from the physics of the devices, the rotating machines are more energy dense than capacitors. Both the capacitor bank and the pulsed alternator have been used to produce pulses lasting 10's of microseconds. The flywheel has been tested in longer term operation. Each of 
these technologies is more than a decade old. Consequently, this demonstrates that the basic physics is correct but not the latest advances in any of the technologies. In addition, key auxiliaries are not shown for each of the technologies: power supply and controls for capacitors; power electronics and controls for pulsed alternator; and motor and controls for the flywheel.

From size and weight considerations, it appears that batteries or rotating machines will likely be the long term storage solution. Batteries have a long history in submarines. From the perspective of maturity of appropriate technology, capacitors and rotating machines are likely near term solutions. Capacitor powered systems may be used in early proof-of-principle demonstrations, because of the experience gained with these systems in the development programs. Rotating machines are the motors and generators on ships. In addition, the new electromagnetic aircraft launch system, which is being installed on carriers uses rotating machines for storage for the high power pulsed load. So, each of these technologies is mature and each has been chosen for shipboard application.

\section{A. Granularity of Storage}

All of the ship-appropriate approaches to storage technology are granular. Therefore, the storage system is comprised of a number of discrete, nearly identical components. Thus, granularity is beneficial for good design, but when the degree of granularity is imposed by the technology rather than being a choice of the designer, some accommodations may be required.

Batteries have a minimum fixed level of granularity, a single cell. The cell voltage is approximately fixed when the battery chemistry is selected [11]. The voltage of a single cell is typically $<5 \mathrm{~V}$ and is a fundamental consequence of the dominant electrochemical reaction. Typical bus voltages will be at least $500-1000 \mathrm{~V}$ indicating the need for $100-200$ of these cells connected in series to provide a voltage sufficient for a DC bus. Future buses may operate at voltages as high as $20 \mathrm{kV}$ to reduce cable weight and to take full advantage of emerging wide bandgap power electronics. This advance would require the series connection of more than 4000 cells. The resistance and inductance of such a string can no longer be ignored and may degrade power delivery.

In addition, several of these strings of cells in series are used in parallel to build up to the required power level, especially for high power applications and to build up the required energy for the lower power applications. Practical integration factors, such as bus work, mounting, maintenance access, monitoring and cooling systems increase the system volume so the energy density of a large system is much less than that of a single cell.

Reliability is another issue of significance when the number of cells required reaches the thousands. The system must be engineered so that the failure of a single cell does not fail an entire series connected string and lead to a cascade failure as the load shifts to parallel strings and increases their discharge rates.

Safety is a concern whenever there is a large amount of stored energy. Li-ion batteries, for example, have a demonstrated catastrophic failure mode; they are extremely sensitive to overcharging; this failure mode requires a complex battery protection system to mitigate that problem. The battery management system further reduces the overall energy storage density. Recently, non-flammable electrolytes have been introduced in $\mathrm{LiFePO}_{4}$ batteries; however, these batteries have a $30 \%$ lower energy density relative to the previous generation.

But as shown in Figure 3, large scale battery systems have been constructed and are operational.

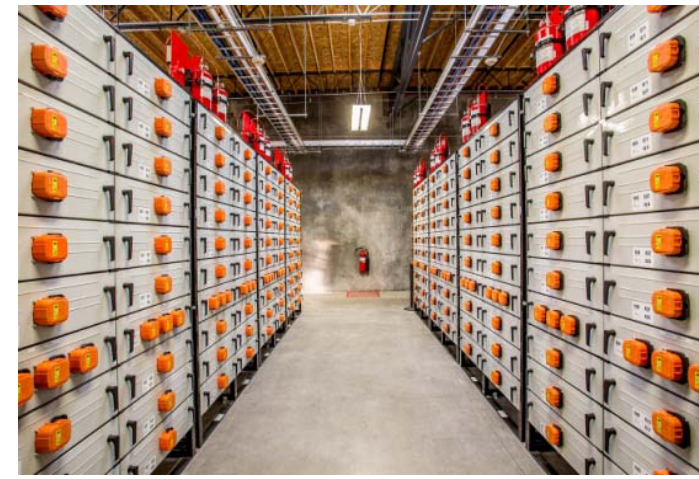

(a) Single aisle of batteries

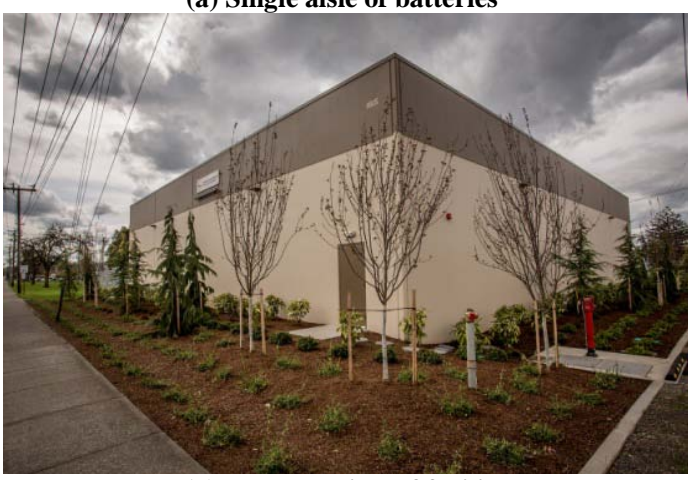

(b) External view of facility

Figure 3 (a) \& (b): Internal and External View of a 5 MW Lithium ion energy storage facility in Oregon.

Rotating electrical machines can be designed to the specific granularity [12] needed for the application. Motors on ships, for example, range from a fraction of one horsepower for small servo motors to thousands of horsepower for propulsion. The granularity is chosen by the designer to be optimal for the application. Having several flywheel/generators rather than a single large one is beneficial from the sheer size and practicality of fitting it in a given volume within a ship. This is particularly significant if one imposes the prudent requirement of replacement via standard hatches. Multiple independent units can provide redundancy with the associated fault tolerance. Beyond this, there is an economy of scale which drives one to relatively few larger 
units. Thus, the granularity in the case of rotating machines can be optimized for a given application.

Safety is also a consideration for rotating machines. The US government funded a major study of safe design of flywheels which has led to a standard for composite flywheel manufacturing. Higher power motors and generators need to be firmly attached to the ship to withstand anticipated large torque excursions. In addition, high torque mechanical couplings must be guarded to eliminate collateral damage in the event of catastrophic failure. These issues are no different on ships than they would be on shore, so designers can incorporate decades of experience with a large number of systems.

Capacitor storage systems are modular at the size of a capacitor. Like for rotating machines, that modularity is to a large extent controllable by the designer. For higher voltage pulsed applications, the capacitor is typically a metal film separated by an appropriate dielectric, often liquid filled to eliminate discharges from metallic edges. Leading designs have long life and low inductance.

Safety issues with capacitors are generally electrical, i.e. shock hazard. They must be isolated when in use and grounded when not.

\section{STORAGE ADVANTAGES IN NORMAL OPERATION}

\section{A. Sudden Loss of Generator}

Simulations have been performed to assess the effects of adding storage to an ac bus and to a dc bus to maintain operation in the event of an intermittent outage by a generator $[13,14]$. The ac system is shown in Figure 4. The goal of this simulation is to demonstrate a restoration of power to the distribution bus by the flywheel energy storage system (FESS) [15] unit through the corresponding load center transformer.

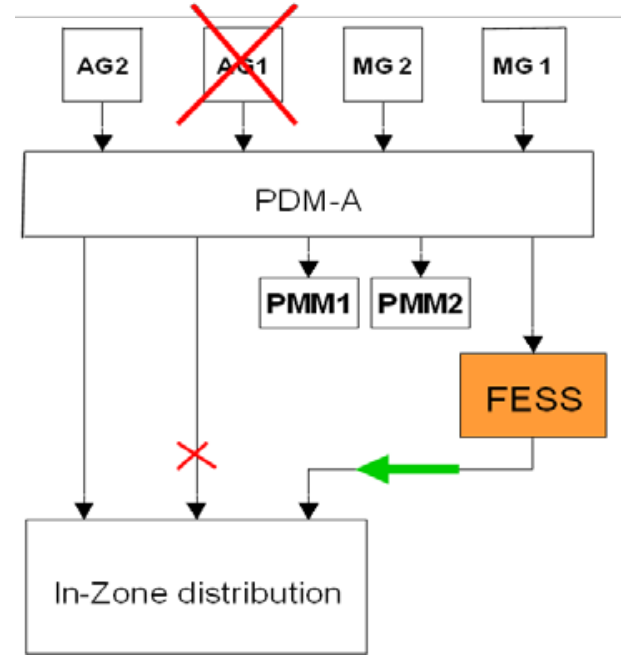

Figure 4: Set-up of simulation of loss of power generation module.

These results, shown in Figure 5, underscore the fact that switching megawatts of ac power typically generates large voltage and current transients. These can be sufficiently large to cause damage. It should be noted that switching surges exist in all power systems. For land-based systems, standard switching surge shapes are specified and the electrical insulation of components attached to the system is designed to withstand repeated switching surges.

An interesting challenge not yet fully explored is shipboard insulation coordination [16, 17]. For land-based systems the highest voltage tests for system insulation are tests on the pulses nominally induced by lightning. The second highest voltage tests are to demonstrate immunity to transients introduced by switching. Lightning tests are important, because the land-based power grid is widely distributed, enhancing its vulnerability to voltage surges commensurate with lightning. Many factors contribute to making the effects of lightning on a ship power system different from those on the terrestrial grid. This difference suggests the possibility that switching-induced transients may be the most significant driver of electrical insulation on ships. The distinction may be significant as it affects the size and weight of the ship power system. This is an area of continuing research. 


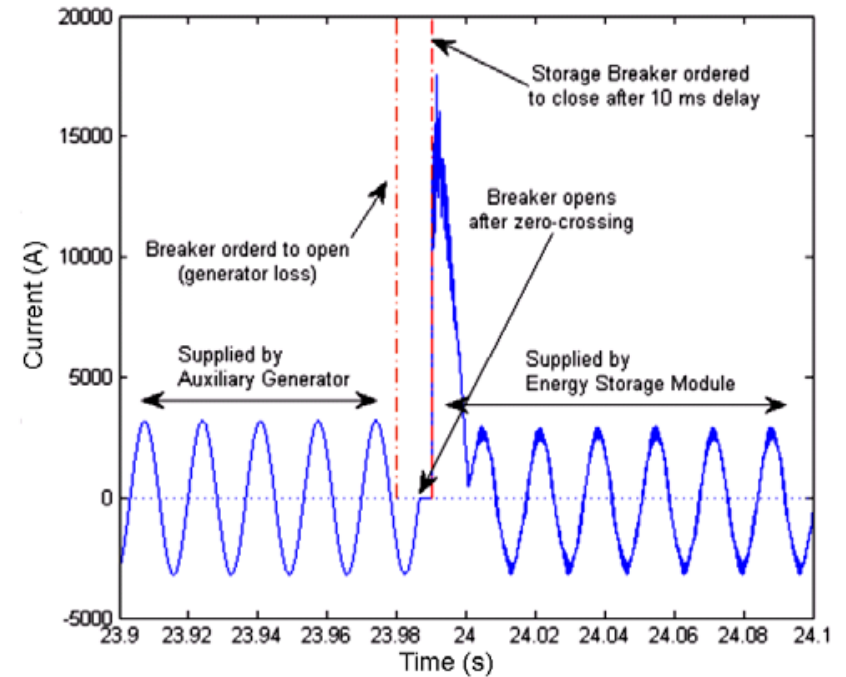

Figure 5: Current change during energy transfer.

Energy storage can also be used to provide ride through power if a gas turbine fails. The simulation for such behavior is shown in Figure 6. The scenario simulated in this case is the removal of a turbine from the system at the two second mark on the graph. At that point two flywheel systems pick up the load and carry it until the turbine can be brought back on line.

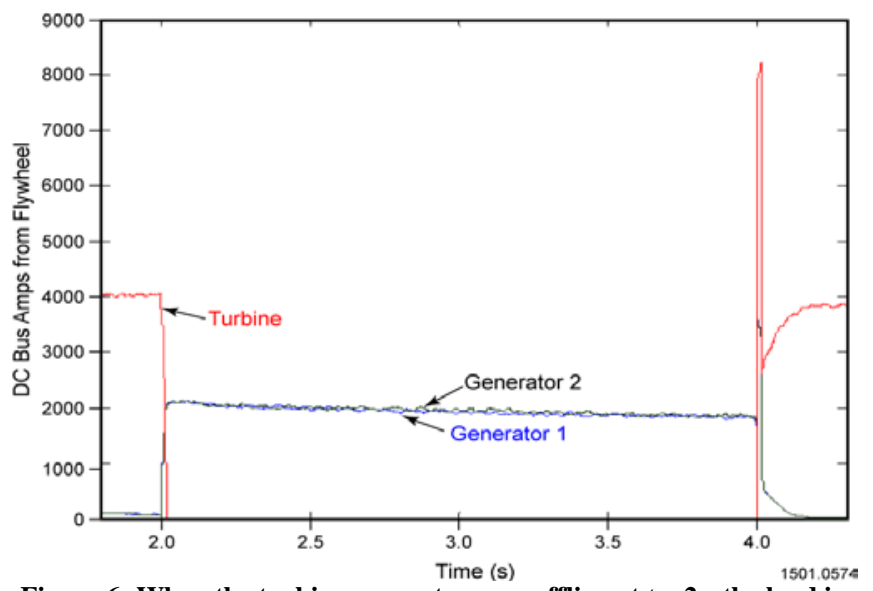

Figure 6: When the turbine generator goes offline at $t=2 \mathrm{~s}$ the load is carried by the two flywheel generators (Generator 1 and Generator 2). At $t=4 \mathrm{~s}$, the turbine generator is re-connected and, after an initial transient current spike, picks up the load again.

\section{B. 1 MW step load}

One of the stresses on a power system that can lead to failures is the switching on or off of large loads. If these are not well managed, one risks applying excessive torque to the generator and turbine shafts causing the control system to turn off the power system to avoid catastrophic damage to these key components. In this case, a dc system was investigated and both the variation in generator frequency and the variation in dc voltage were predicted, Figure 7. Modeling helps prevent inappropriate designs [18].
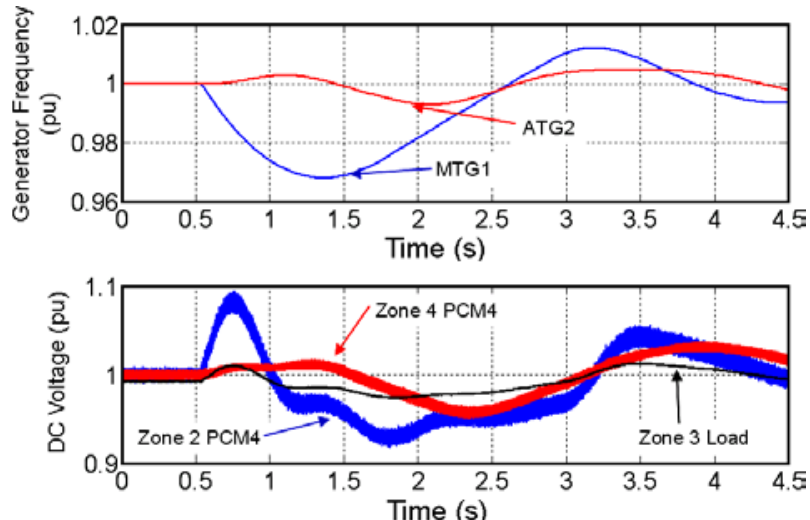

Figure 7: Generator frequency and bus voltage during pulse load charging event. The upper chart shows that the frequency changes in both the main and auxiliary generators of about $3 \%$. The lower traces show the voltage changes by almost $10 \%$.

Subsequent experimental and theoretical work has generalized these results. The generators that supply the power system have inertia. The rotor is a rotating mass, just like a flywheel. Consequently, some energy can be added to the rotational energy or taken from it before the rotor speed changes sufficiently that it is necessary to disconnect them from the circuit to protect them from damage. The greater the inertia, the more energy variation the generators can handle gracefully. This provides some time for control action. The control can exploit a storage technology purposely developed for this application. Another alternative is to use existing HVAC and/or propulsions systems to provide the same function of the storage system until a gas turbine can be brought on line or turned off, which ever the load variation demands. The trade space among generator inertia, speed of the control system and the safe operating margin on the generators has been developed theoretically. In addition, the effects of control system latency have been studied experimentally in a grid with high inertia. Experiments are still needed on low inertia grids as would be used on ships.

\section{Pulse load discharge/charge}

A key area in which energy storage is widely recognized as being necessary is to serve large transient loads. In this case, the energy can be accumulated over time and be used in a short time for a high power load.

To assess the feasibility of employing a dedicated energy storage device to minimize the impact of pulsed-load charging disturbances to the power system performance, a simulation study was conducted in which the ship's ring bus was subjected to a large, sudden load demand by a generic pulsedload charging circuit. This 30 MW step load caused large frequency deviations in the generators connected to the bus. The goal of this study was to reduce such deviations to the MIL-STD-1399 transient frequency tolerance of $\pm 4 \%$ by applying energy from the storage device in a controlled fashion.

The simulations showed that the application of storage to mitigate the effect of pulsed loads was, as expected, quite 
feasible. A system was considered that could not maintain the standard frequency tolerance during a transient without storage. With storage, the system was compliant with the military standard.

\section{A COST APPROACH TO STORAGE SYSTEM DESIGN}

In general, discussions concerning energy storage implicitly refer to situations in which a storage technology other than fuel is added to the ship. However, it is also important to consider when the additional technology may not be necessary, because when it is not necessary, the cost, size, and weight of the power system are all smaller.

There are clearly situations in which operating solely on fuel is not an option. An historical example is the submarine. The occasional need to operate the submarine as quietly as possible and the requirement for alternate propulsion power make it worth carrying large numbers of batteries. They take up valuable space and they require fuel to transport them when they are not being used, but the benefit outweighs the cost. Justifying that the benefit exceeds cost is obviously appropriate for all storage applications.

In addition to the submarine example, there are other fundamental compelling reasons for some degree of storage. One of the reasons is that the fuel-to-electricity storage option is not reversible. Reversibility can be important for efficient operation in some cases. An emerging example is an electric gun. When the projectile leaves the barrel of an electromagnetic gun, considerable energy is stored in the collapsing magnetic field between the rails. In a reversible system, this energy can be captured, stored, and used in the next shot or for other purposes on the ship.

A second reason for storage is that, with storage, it is not necessary to design the power system to meet the transient peak load. Having to do so would lead to a power system that could well be significantly oversized for the ship except for a very small fraction of its lifetime. A storage system, however, can accumulate energy over time from the ship's power system, i.e., from the ship's fuel. The stored energy can then be used to power a transient peak load. This may be due to an absolute peak such as may be produced by an EM gun or a high powered laser, or a relative peak such as to start a backup gas turbine when the load exceeds the supply.

A third reason is that the ramp rates of some loads may be beyond the dynamic range of gas turbines. In that case, storage, with fast charge and/or discharge rates is needed to buffer a gas turbine from the transient.

When one has storage technology installed for good fundamental reasons, that capability opens the door to using the technology in other beneficial ways. These other uses may not be sufficiently cost effective to justify the initial expense, but they could be useful.
So, the decision steps are first to determine if storage is necessary. When the answer is affirmative, the possibility of other beneficial uses of the storage system should be explored. For these situations, an analysis can be done to quantify the trade space. A simplified summary of this analysis is captured in equation (1),

$$
W_{\text {avail }}=P_{2} t_{2} \beta^{2}\left(1-\frac{\Delta t}{\tau_{1}}-\left(\frac{\Delta t}{\tau_{2}}\right)^{2}\right) .
$$

In this equation, which describes the non-fuel storage technology, $\mathrm{P}_{2}$ is the power with which the energy was introduced into the storage device, and $t_{2}$ is the time over which it was deposited. Obviously, this is the input energy using average values. A more rigorous approach would involve the integration of the power over time. The efficiency of inserting or extracting energy is indicated by $\beta^{2}, \Delta t$ is the time the energy has been stored, and the decay rate is best represented by a quadratic dependence on storage time, and thus utilizes two time constants $\tau_{1}$ and $\tau_{2}$.

This equation highlights the fact that one always loses energy in storage. This does not imply that it is always less efficient to use storage. This seeming contradiction is due to the specific fuel consumption of gas turbines depicted in Figure 8.

As can be seen in this figure, the specific fuel consumption is highly nonlinear and usually very high at low power levels. So, there are situations in which it is more fuel efficient to store energy when a gas turbine is operating near it best efficiency and use the stored energy rather than use a gas turbine at low load. This suggests that for energy efficiency one would use a smaller turbine and storage for varying loads rather than use a larger turbine alone for load leveling. Energy storage is desirable if and only if the available energy as penalized in (1) exceeds the energy computed if taken directly from the gas turbine. Energy storage is always preferred over running a gas turbine at low power level for load leveling.

Guidance has been quantified as to when to use storage and when to depend on a gas turbine alone. The guidance is summarized in the example chart in Figure 9. In this figure, it can be seen that some duty cycles in which the use of fuel is more economical and others in which storage is the more efficient choice. 


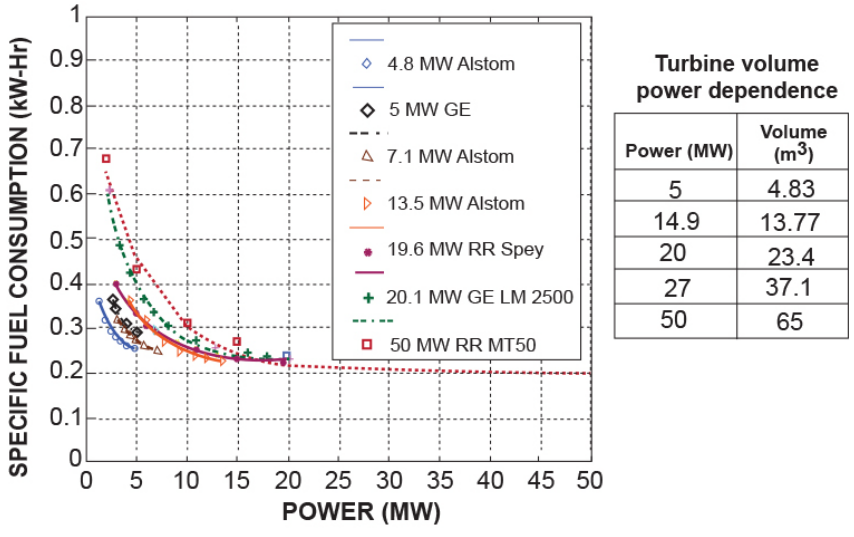

Figure 8: Typical gas turbine specific fuel consumption as a function of power. The high consumption at low power provides an opportunity for storage.

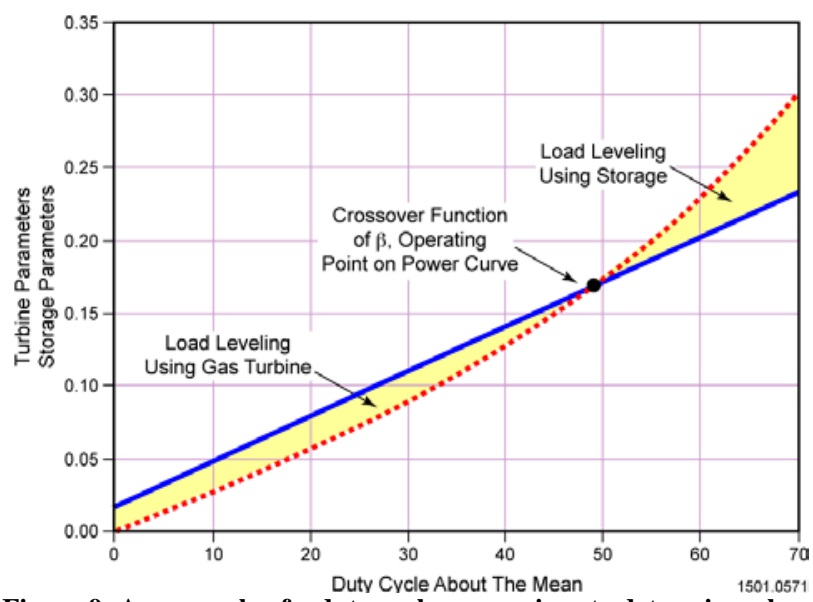

Figure 9: An example of a duty cycle comparison to determine when energy storage is appropriate for load leveling. The details of the curves

depend on the storage technology. This is a flywheel example. The vertical axis is listed in dimensionless numbers that account for such parameters as the specific fuel consumption of the gas turbine and the losses in the flywheel.

\section{EMERGING MULTIPURPOSE STORAGE SYSTEMS}

The first published work [19] that showed the technical feasibility of multi-usage storage systems addressed firing a free electron laser or an electromagnetic gun or enhancing the power quality of the ship power grid from a single storage system. That early work has been broadened and advanced by many in the development community. Today, the more sophisticated concept is called by some and "energy magazine". The term is a shorthand description to communicate that energy is being stored to power the pulsed loads when needed and to enhance routine operation when possible.

This approach to energy management was likely stimulated by the design of the emerging electromagnetic launch systems being installed in carriers for aircraft launch. No mature systems yet exist for other applications. This is an area of active research, primarily via modeling and simulation.
An important initial step in the assessment is to predict the impact of charging a storage system for a large pulsed load on the size of the Energy Magazine in a number of bus configurations and charging profiles. The pulsed power supply (PPS) for an electromagnetic launcher (EML) is anticipated to be one of the most demanding future power requirements.

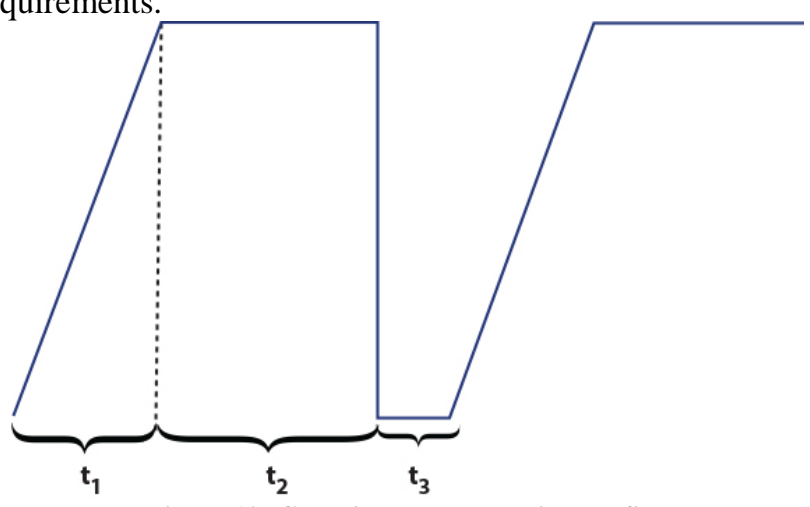

Figure 10: Capacitor bank charging profile.

A notional example multi-shot charging profile for a capacitor-based PPS is shown in Figure 10. A single charge cycle starts off in a current limited mode. This mode ramps up the voltage on the capacitors (time interval $t_{1}$ in the figure). To minimize the impact on the shipboard power system, at some time ( $\mathrm{t}_{2}$ in figure) the charging cycle transitions into a power limited charging mode. The EML fires during the interval $t_{3}$ and the launcher is prepared for the next shot.

For most pulsed power capacitors, hardware lifetime considerations limit the duration of a charge cycle and dwell time before firing. For high shot rates, the peak power of this charge cycle can use a very large fraction of the available shipboard power.

To model such a system, an aggregated load can be used to represent the power requirements for all ship system loads other than the PPS. Shipboard power generation and storage for general use are also represented in aggregate. The simplified system is shown in Figure 11.

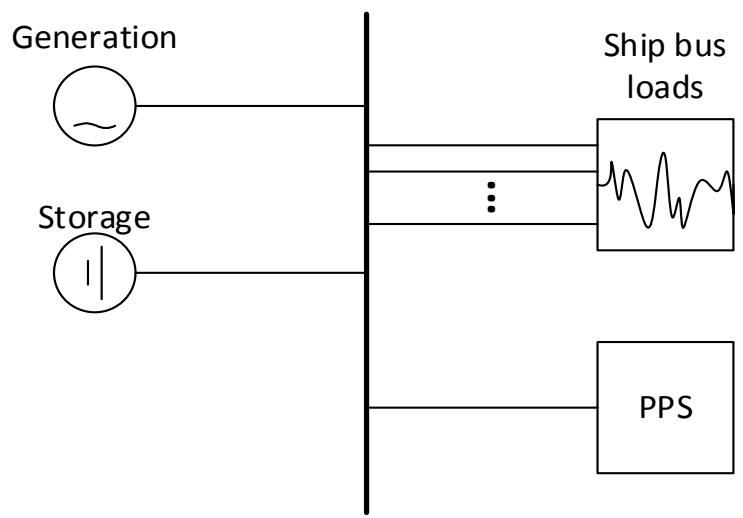

Figure 11: Simplified block diagram of system whose behavior is simulated. 
This model is for a power bus system that is common to all loads. In this case the energy magazine provides storage and power leveling for all ship loads. The pulsed power supply (PPS) provides power to the high power transient loads while the remainder of the ship is aggregated into a stochastically varying load. The model results are presented as conventional "per unit" normalized results as the observed phenomena are expected to be scalable over a reasonable range of voltages and currents. For completeness, the base values are: Power $-78 \mathrm{MW}$; Voltage $-18 \mathrm{kV}$; Current - 4.33 kA; Energy - 78 MJ; Resistance - $4.15 \Omega$.

In this configuration the energy magazine's primary function is to limit the power ramp rate seen by the generator(s). For this simulation it is assumed that the per generator ramp rate limit should be no more than $1 \mathrm{MW} / \mathrm{s}$ and that two identical generators are actively supplying power and that they will share power equally. Therefore, the energy store limits the maximum ramp rate to the generation block to 2 $\mathrm{MW} / \mathrm{s}$.

To provide a reasonable representation of the stochastic nature of future ship power demand variations, a bounded random walk approach was used to generate the notional power variation. Parameters for profile creation were step amplitude changes: Less than $0.6 \mathrm{pu}$ and greater than $0.3 \mathrm{pu}$; number of points: 200 (1 point per second); maximum change point-to-point: $0.05 \mathrm{pu}$; start to finish change: $0.03 \mathrm{pu}$. As shown in Figure 12, this set of assumptions provides what appears to be a reasonable first approximation of future variations. Obviously the sensitivity to the profile can be estimated by iteratin $g$ the simulation with changes in the chosen parameters.

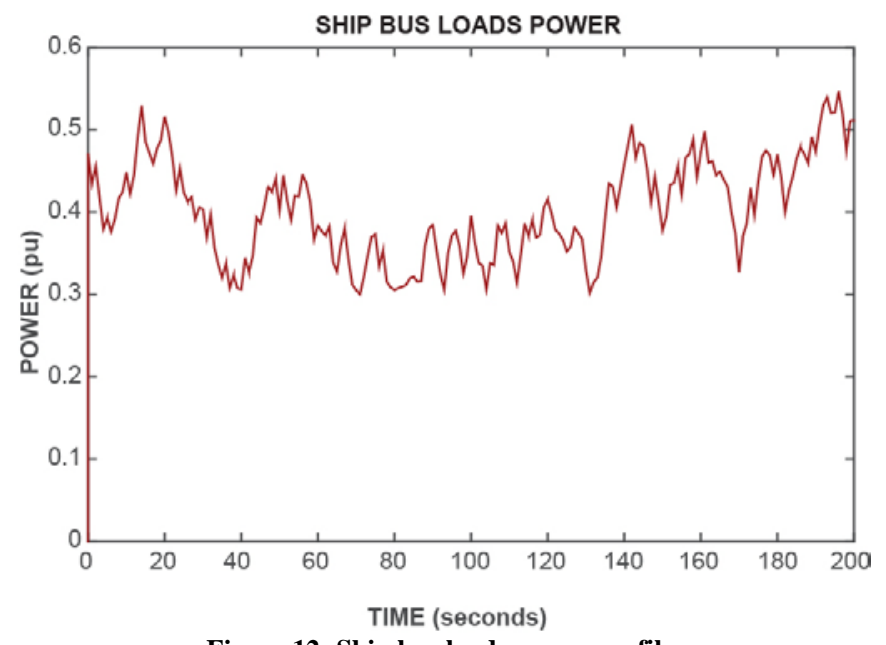

Figure 12: Ship bus loads power profile.

The second important input to the simulation is the dynamics of a large pulsed load. To simulate a representative case, it was assumed that the high power system was discharged 16 times at a rate of 10 discharges per second, as shown in Figure 13.

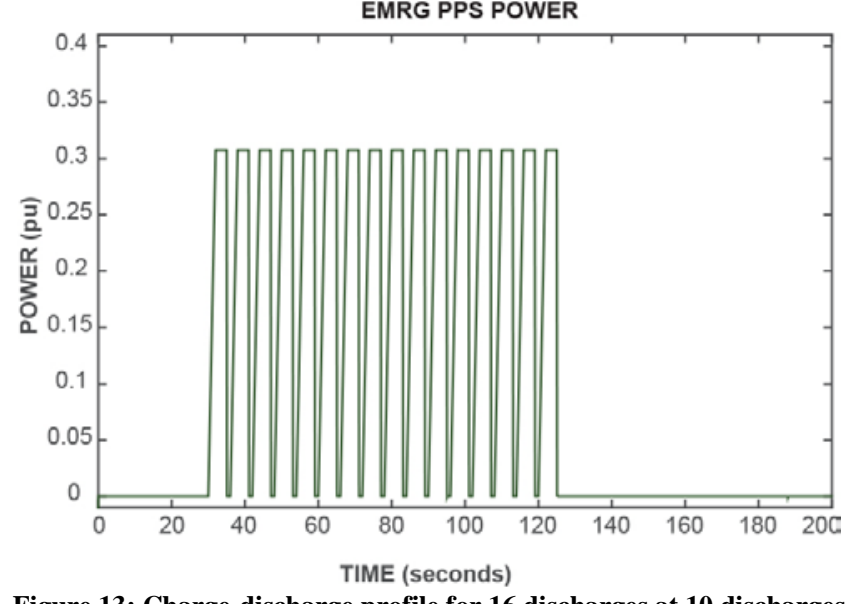

Figure 13: Charge-discharge profile for 16 discharges at 10 discharges per second. Peak power is $24 \mathrm{MW}$.

The simulation permits the prediction of the system performance with and without the pulsed load. Figures 14-16 show the storage power, energy, and the generator power simply to maintain the ship with no high power loads. In this application, the storage is simply providing transient support for the generators. This is highlighted in Figure 16 that shows the dynamic differences between the generator power demand and the total load demand. The difference is met by the storage system.

Figures 17-20 again show the storage power and energy and the generator power while the ship is operating normally and a burst of high power discharges of the storage system occurs. Figure 19 shows important benefits of the storage system during the high power discharges. The generator power draw is relatively slowly varying while the significant variation in total system power demand is being met by the storage system. Additional assessments have quantified the benefits of some precharging prior to the full discharge sequence and the energy handling required if one wanted to reclaim the energy of a full charge rather than discharge it into a pulsed load.

The modeling highlighted here focuses on a simplified model to clarify results. This type of modeling is being conducted in much more complex ship power system architectures for which conventional computation times can be excessive. As a result, an automated partitioning and multirate approaches have been developed to permit significantly faster computations [20-22].

In addition, additional constituents for the energy magazine are being investigated. In this case, capacitors were used for load leveling. But, as the precise nature of the pulsed loads become clearer, it is likely that some combination of batteries [23, 24], rotating machines [25, 27], and capacitors [28] will likely provide the most effective solution. In addition, it is possible that a gas turbine dedicated to the energy magazine may make the entire system smaller and lighter for a range of applications. 
Another important aspect being simulated is the degree to which the energy magazine should be a distributed system. Distributing the system may provide as smaller more robust system. A challenge, however, is the system inductance in distributed systems for high rates of change of currents. With rapid large charging and discharging, shorter, low inductance connections to the load are beneficial.

\section{Simulation results with ship loads only:}
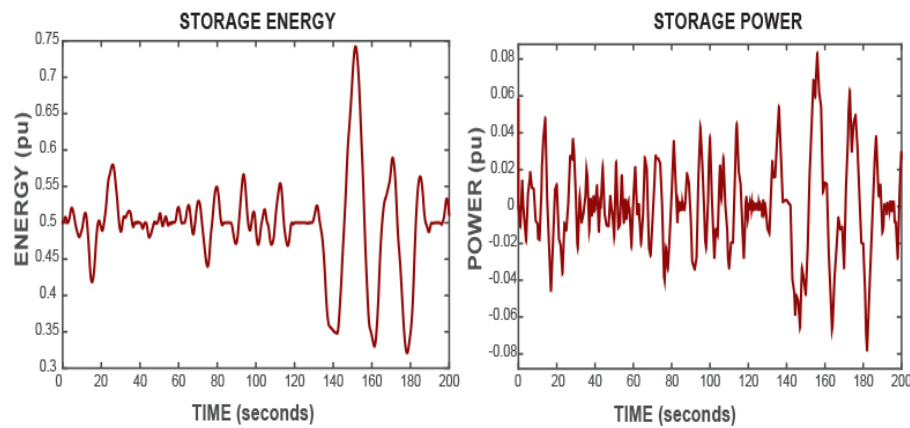

Figure 14: Energy Magazine storage power and energy vs. time.

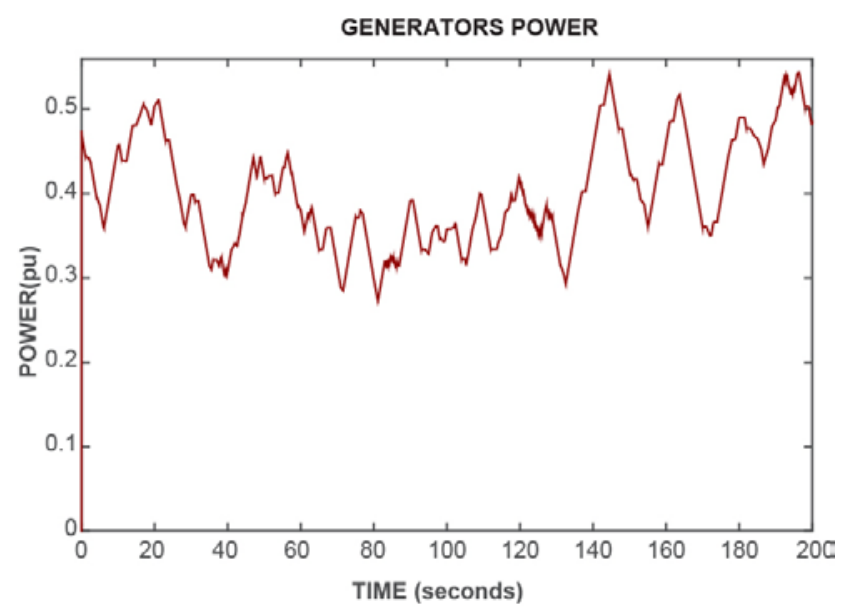

Figure 15: Power output of generators.

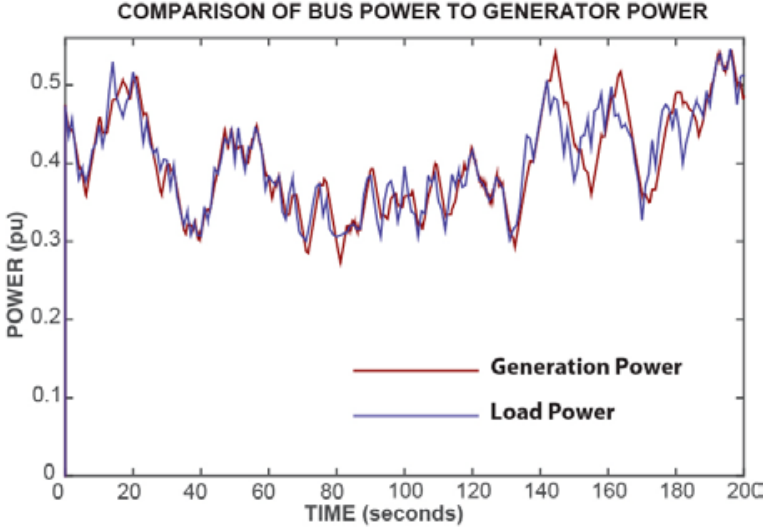

Figure 16: Plot of generator power versus sum of load power.

Simulation results with ship loads and railgun shot series:
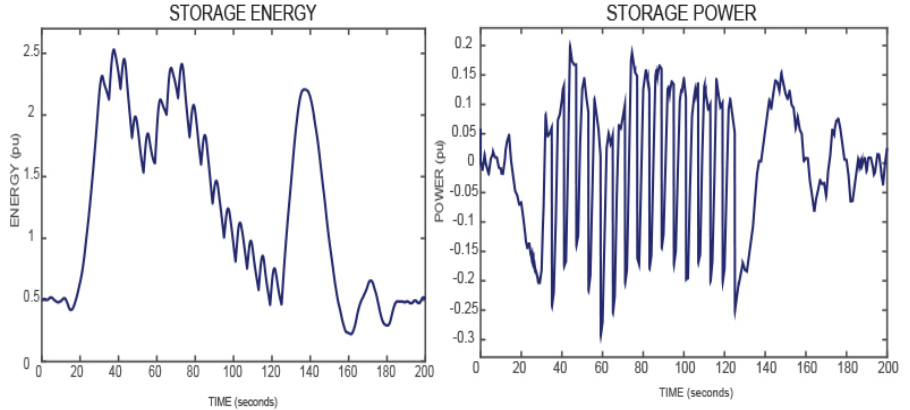

Figure 17: Energy Magazine storage power and energy vs. time.

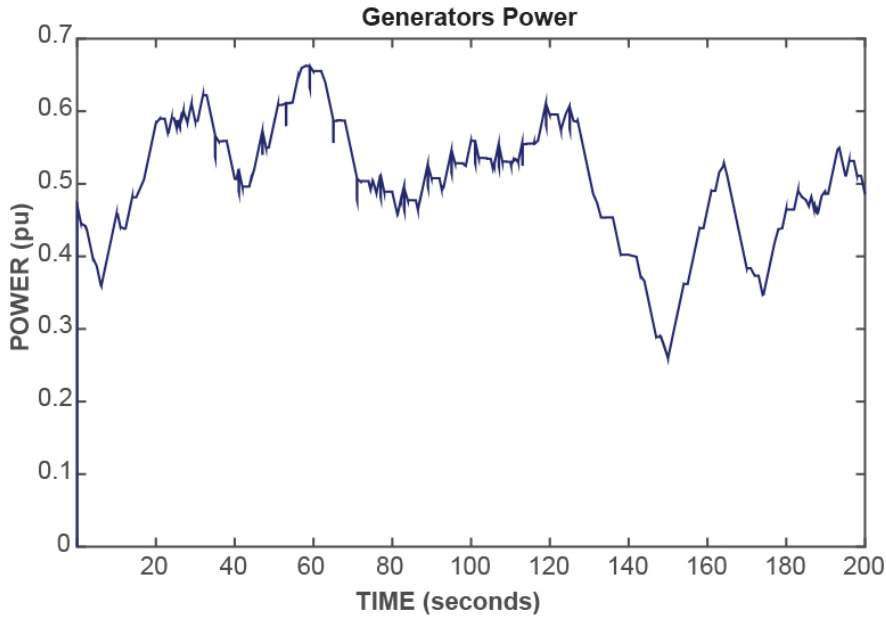

Figure 18: Power output of generators.

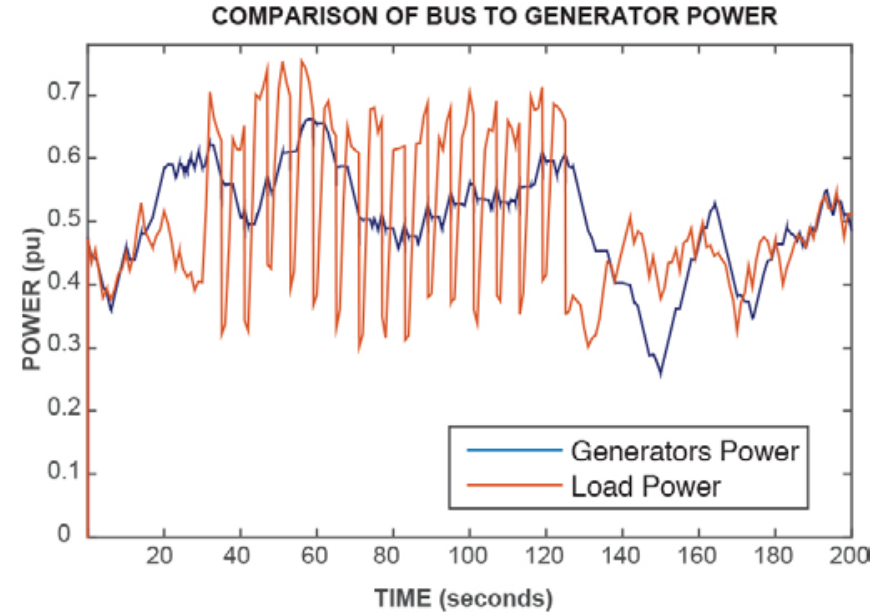

Figure 19: Plot of generator power versus sum of load power. 


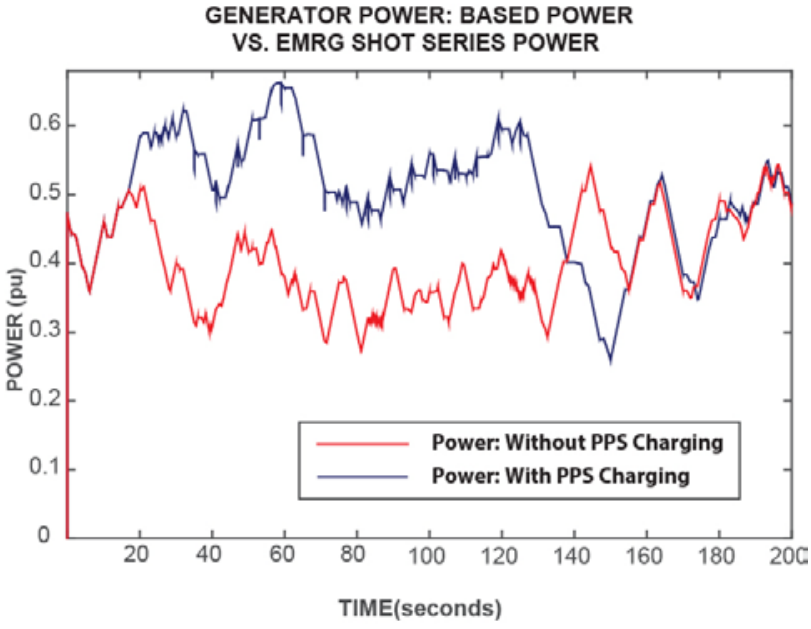

Figure 20: Comparison of generator power requirements with and without PPS charging.

\section{SUMMARY}

The increasing use of electricity on ships has provided a demand for storage as the ship is an isolated power system that must maintain stability and power quality. In addition, there is a growing demand for high power pulses from the power system. In this case, storage can make it possible to operate for short times at powers significantly higher than the rated steady-state power.

Given the state of technology development and ship demand, fuel, capacitors, rotating machines and batteries are all used for shipboard applications. Given the different attributes of each technology, there is not a generic best approach to storage. Rather, the challenge today is to address storage at the ship system rather than the component level. The best combination of ship storage systems powers all loads and achieves high power quality and reliability at the lowest possible cost, weight and size. The community is learning that storage is best selected in a system study, not a component study.

\section{References}

[1] M.R. Doyle, D.J. Samuel, T. Conway, and R.R. Klimowski, "Electromagnetic aircraft launch system EMALS," IEEE Transactions on Magnetics, vol. 31, pp. 528-533, January 1995.

[2] H.E. Jordan, R.C. Zowarka, and S.B. Pratap, "Nine-phase armature windings design, test, and harmonic analysis," IEEE Transactions on Magnetics, vol. 41, pp. 299-302, January 2005.

[3] Y. Khersonsky, N. Hingorani, and K.L. Peterson, "IEEE Electric Ship Technologies initiative,” Petroleum and Chemical Industry Conference 2009, Anaheim, CA, pp. 1-10, September 2009 [PCIC 2009 Record of Conference Papers-Industry Applications Society 56th Annual].

[4] T. Ericsen, "Engineering 'Total Electric Ship'," IEEE Petroleum and Chemical Industry Technical Conference 2007, Calgary, Alberta, Canada, pp. 1-6, September 2007 [PCIC 2007].

[5] R.E. Hebner, "Electric ship power system-research at the University of Texas at Austin,” 2005 IEEE Electric Ship Technologies Symposium, Philadelphia, PA, pp. 34-38, July 2005, [2005 IEEE ESTS].
[6] K.R. Davey and R.E. Hebner, "A fundamental look at energy storage focusing primarily on flywheels and superconducting energy storage," Electric Energy Storage Applications and Technologies Conference, San Francisco, CA, pp. 17-18, October 2003, [EESAT 2003 Conference].

[7] Y-L Li, I.A. Kinlock, A. H. Windle, "Direct Spinning of Carbon Nanotube Fibers from Chemical Vapor Deposition Synthesis,” Science, vol. 304 pp. 276-278, 9 April 2004.

[8] F. H. Gojny, M. H. G. Wichmann, B. Fiedler, and K. Schulte, "Influence of different carbon nanotubes on the mechanical properties of epoxy matrix composites - A comparative study,” Composites S\&T, vol. 65, pp. 2300-2313, 2005.

[9] B. Kang and G. Ceder, "Battery materials for ultrafast charging and discharging,” Nature, vol. 458, pp. 190-193, 2009.

[10] J-Y. Lou and Y-Y Xia, “Aqueous Lithium Ion Battery LiTi2(PO4)3/LiMn2O4 with High Power and Energy Densities as well as Superior Cycling Stabilities," Advanced Functional Materials, vol. 17, pp.3877-3884, 2007.

[11] B. Lindemark, "Individual cell voltage equalizers (ICE) for reliable battery performance,” 1991 Telecommunications Energy Conference, Kyoto, Japan, pp. 196-201, November 1991, [INTELEC 1991-13th International Conference].

[12] S. Pratap, R. Zowarka, T. Hotz, and S. Pish, "Synchronization of multiple pulsed alternators discharging into an EM launcher," Electromagnetic Launch Technology, La Jolla, CA, July 2014, [2014 EML-17th International Sypmosium].

[13] J. McGroarty, J. Schmeller, R. Hockney, and M. Polimeno, "Flywheel energy storage system for electric start and an all-electric ship," Electric Ship Technologies Symposium, Philadelphia, PA, pp. 400406, July 2005, [2005 IEEE ESTS].

[14] C. Xie and C. Zhang, "Research on the ship electric propulsion system network power quality with flywheel energy storage," 2010 AsiaPacific Power and Energy Engineering Conference, Chengdu, China, pp. 1-3, March 2010, [2010 APPEEC].

[15] R.E. Hebner, J. Beno, and A. Walls, " Flywheel batteries come around again,” IEEE Spectrum, vol. 39, pp. 46-51, April 2002.

[16] H. Murase, S. Okabe, T. Kumai, and H. Takakura, "Systemization of insulation design technology for various electric power apparatus," IEEE Transactions on Dielectrics and Electrical Insulation, vol. 13, pp. 400-407, April 2006.

[17] R.W. Hotchkiss and A.T. Haa, "Electric ship surge environment," Electric Ship Technology Symposium, Arlington, VA, pp. 301-308, May 2007 [2007 IEEE ESTS].

[18] J.R. LeSage, R.G. Longoria, and W. Shutt, "Power system stability analysis of synthesized complex impedance loads on an electric ship," Electric Ship Technologies Symposium, Alexandria, VA, pp. 34-37, April 2011, [2011 IEEE ESTS].

[19] L.N. Domaschk, A. Ouroua, R.E. Hebner, and O.E. Bowlin, "Coordination of large pulsed loads on future electric ships," IEEE Transactions on Magnetics, vol. 43, pp. 450-455, January 2007.

[20] R.E. Crosbie, J.J. Zenor, R. Bednar, and D. Word, "Multi-rate simulation techniques for electrip ship design," Electric Ship Technology Symposium, Arlington, VA, pp. 384-389, May 2007 [2007 IEEE ESTS].

[21] F.M. Uriarte and R.E. Hebner, "Development of a multicore power system simulator for ship systems," Electric Ship Technologies Symposium, Alexandria, VA, pp. 106-110, April 2011, [2011 IEEE ESTS]. 
[22] F.M. Uriarte, R.E. Hebner, and A.L. Gattozzi, "Accelerating the simulation of shipboard power systems," Grand Challenges in Modeling \& Simulation, The Hague, Netherlands, June 2011.

[23] Y.Y. Chen, K. Nevchev, and C. Persad, "Pulsed power performance of saft very high-power lithium-ion batteries under high-temperature conditions,” 2007 Conference on Plasma Science, Albuquerque, NM, pp. 247, June 2007, [IEEE ICOPS 2007-34th International Conference].

[24] A. Sitzman, D. Surls, and J. Mallick, "Modification and testing of a battery-inductor repetitive pulsed power supply for a small railgun," 2007 Conference on Plasma Science, Albuquerque, NM, pp. 1014, June 2007, [IEEE ICOPS 2007-34th International Conference].

[25] R.E. Hebner, J.A. Pappas, J.R. Kitzmiller, K.R. Davey, J.D. Herbst, A. Ouroua, and J.H. Beno, "An electromagnetic gun power supply as a component of an electric ship power system," ASNE High Powered Weapon Systems for Electric Ship 2004, Annapolis, MD, December 2004.

[26] S. Kulkarni and S. Santoso, "Impact of pulse loads on electric ship power system: With and without flywheel energy storage systems," Electric Ship Technologies Symposium, Baltimore, MD, pp. 568-573, April 2009, [2009 IEEE ESTS].

[27] C. Ye, K. Yu, Z. Lou, and Y. Pan, "Investigation of self-excitation and discharge processes in an air-core pulsed alternator," IEEE Transactions on Magnetics, vol. 46, pp. 150-154, January 2010.

[28] J.S. Bernardes, M.F. Stumborg, and T.E. Jean, “Analysis of a capacitorbased pulsed-power system for driving long-range electromagnetic guns,” IEEE Transaction on Magnetics, vol. 39, pp. 486-490, January 2003.

Robert E. Hebner, Ph.D., IEEE Fellow, (S'70-M'71SM'83-F'93) received the B.S. degree in physics from Saint Mary's University, San Antonio, TX, in 1967 and the M.S. and Ph.D. degrees in physics from the University of Missouri, Rolla, in 1969 and 1971, respectively. He is Director of the Center for Electromechanics at the University of Texas at Austin. The Center develops technology, primarily for novel motors, generators, and suspension components, and teams with companies to get the technology into the market. Previously, he was the acting Director of the U.S. National Institute of Standards and Technology (NIST). In addition, he has directed NIST's Electronic and Electrical Engineering Laboratory, a laboratory with a staff of more than 250.

Kent Davey, Ph.D., IEEE Fellow, is an independent consultant in electromechanics and electromagnetics. Until recently he was also an adjunct Professor with the School of Physics, University of Houston as well as the Georgia Health Science University. He is a Fellow with the Institute of Electrical and Electronic Engineers and Editor of IEEE Transactions on Magnetics. He specializes in the interaction of electric and magnetic fields with matter and in the numerical computation of electric and magnetic fields. He was formerly Senior Research Scientist with the Center of Electromechanics, University of Texas, Austin. Before that he was the Chief Research Scientist for American Maglev, and a tenured Associate Professor in Electrical Engineering at Georgia Institute of Technology. He has over 100 refereed journal papers with IEEE and another 90 conference publications.
Mr. John Herbst, B.S.M.E., joined the University of Texas Center for Electromechanics (UT-CEM) in 1985, he is currently an Associate Director. Presently, he serves as CoPrincipal Investigator for the Electric Ship Research and Development Consortium, a long-term technology development program sponsored by the Office of Naval Research. His research interests include high performance rotating electric machines, turbo-machinery packaging and integration, flywheel energy storage, advanced power conversion technologies, high performance composite structures, microgrid power systems, and pulsed power technologies.

David Hall, Ph.D., (M’83-SM'97) received his B.S. degree in electrical engineering from Carnegie-Mellon University in 1983 and his M.S. degree in electrical engineering from the Air Force Institute of Technology in 1984. He received a Ph.D. in electrical engineering from the University of Pittsburgh in 1997. He served as an officer in the United States Air Force from 1983 through 1988. He joined the Westinghouse Science and Technology Center in Pittsburgh, PA in 1989 and joined Curtiss-Wright in 2003. He is currently a Principal Engineer at Curtiss-Wright Advanced Products and Systems in Mount Pleasant, Pennsylvania, USA. His current research interests include electric machines, power generation, pulse power, and energy storage, plus linear electric motors, motor drives, and controls. Dr. Hall is a registered professional engineer in the Commonwealth of Pennsylvania, USA. He has authored or coauthored 26 technical papers in conference proceedings or technical journals and holds 8 United States Patents.

Jonathan Hahne, B.S., is a Senior Engineering Scientist as the Center for Electromechanics at the University of Texas at Ausitn. He received his BS in mechanical engineering from the University of Texas at Austin in 1986. During his research career at the University, his primary focus has been the design, manufacturing, and testing of high power and/or high energy density prototype rotating electric machines. Other areas of experience and expertise include electromagnetic launch technology and high performance composite design and manufacturing.

Dwayne D. Surls, M.S. - Bio not available.

Abdelhamid Ouroua, Ph.D., is with the University of Texas, Center for Electromechanics (UT-CEM). He holds B.S, M.S, and $\mathrm{PhD}$ degrees in physics from The University of Sciences and Technology of Algiers, Algeria, the University of California at Los Angeles, and the University of Texas at Austin, respectively. He works on design, analysis, modeling, and simulations of electro-mechanical systems including development of diagnostic systems for high temperature plasmas. Prior to joining UT-CEM he was with Rensselaer Polytechnic Institute where he played a major role in the development, installation, and operation of a 2-million eV heavy ion beam probe diagnostic system (HIBP). He is currently working on the development of a hot calibration 
source for the electron cyclotron emission (ECE) diagnostic system for the ITER tokamak. 